(C) 2018, THE AUTHORS. Published by FASS Inc. and Elsevier Inc. on behalf of the American Dairy Science Association ${ }^{\circledR}$. This is an open access article under the CC BY-NC-ND license (http://creativecommons.org/licenses/by-nc-nd/3.0/).

\title{
Short communication: Model for metritis severity predicts that disease misclassification underestimates projected milk production losses
}

M. M. McCarthy and M. W. Overton ${ }^{1}$

Elanco Animal Health, 2500 Innovation Way, Greenfield, IN 46140

\section{ABSTRACT}

The objective of this research was to determine the effect of disease misclassification on the estimated effect of metritis on milk production. Misclassification introduces bias that usually results in an underestimation of the association between exposure (disease) and the outcome of interest (milk production). This distorted measure of association results from the comparison of an affected population (some of which may not truly be affected) to a nonaffected population (which often includes affected subjects that are unidentified). A convenience sample of DairyComp305 (Valley Agricultural Software, Tulare, CA) data representing 1 yr of calvings $(\mathrm{n}=3,277)$ from 1 Midwestern Holstein herd was used. This herd was chosen because of its ongoing efforts to consistently and completely record all clinical diseases, including the incidence of both mild and severe metritis cases. Metritis was defined as the presence of a flaccid uterus containing fetid fluids or a foul watery discharge within $14 \mathrm{~d}$ of calving. Cows that appeared clinically normal other than the discharge were considered mild and those with systemic signs of disease were classified as severe. The original data set included metritis recorded as mild, severe, or not recorded (NR), where no metritis was observed, and was considered to contain the metritis true severity ( $\mathrm{TrS})$. First, to evaluate the effect of misclassification bias, we retrospectively randomized $45 \%$ of mild metritis to be classified as NR to simulate inconsistent disease recording (IR); then, in a separate model, all mild metritis cases were changed to NR to simulate a situation of very poor disease recording (PR), where only the most severe cases are recorded. The TrS, IR, and PR data sets were analyzed separately in JMP (SAS Institute Inc., Cary, NC). An ANOVA was conducted for second test 305-d mature-equivalent milk projection (2nd305ME), and nonsignificant variables were removed, but the variable metritis was forced into all models. Based upon the TrS model, adjusting for effects of lactation group, month

Received November 20, 2017.

Accepted February 2, 2018

${ }^{1}$ Corresponding author: moverton@elanco.com of calving, dystocia, twins, retained placenta, earlylactation mastitis, displaced abomasum, and significant interactions, a case of mild metritis was associated with $384 \mathrm{~kg}$ less $2 \mathrm{nd} 305 \mathrm{ME}$ and a case of severe metritis was associated with $847 \mathrm{~kg}$ less 2nd305ME compared with no metritis. For the IR model, a case of mild metritis was associated with $315 \mathrm{~kg}$ less 2nd305ME and a case of severe metritis was associated with $758 \mathrm{~kg}$ less 2nd305ME compared with no metritis. For the PR model, severe metritis was associated with $680 \mathrm{~kg}$ less 2nd305ME compared with NR. The IR and PR models underestimated 2nd305ME loss for severe metritis cases by 89 and $166 \mathrm{~kg} / \mathrm{cow}$, and resulted in 180,441 and $330,256 \mathrm{~kg}$ of total milk loss unaccounted for at the herd level, respectively, compared with TrS. Overall, misclassification of metritis cases results in greater bias and largely underestimates the true association between metritis and the consequence costs of the disease.

Key words: metritis severity, misclassification bias, disease consequence

\section{Short Communication}

Dairy producer-recorded disease incidences are typically lower than the disease incidences that are found in the literature (Parker Gaddis et al., 2012). The reduced incidence of disease in herd-recorded data compared with research data likely represents an under recording, or misclassification, of the disease by dairy producers. Metritis is a costly disease that affects early-lactation dairy cows (Sheldon et al., 2009; Liang et al., 2017) and has been associated with negative downstream outcomes, such as reduced milk production, increased culling risk, and impaired reproduction (Lee et al., 1989; Deluyker et al., 1991; Fourichon et al., 2000; Wittrock et al., 2011). Metritis is also one of the most inconsistently diagnosed and recorded diseases on commercial dairy farms (Kelton et al., 1998; Sannmann et al., 2012). Some of the challenges with metritis diagnosis include inconsistent definition of metritis, inconsistent diagnostic approach and effort between herd personnel, and inconsistency in DIM when the disease evaluations are performed (Espadamala et al., 2016). Inconsistencies in disease recording may preclude us from making 
faster advances in understanding the effect of disease on performance, as the failure to record disease affects the measurable performance in the herd by introducing bias into the system. This introduction of bias can result from failing to record metritis, failing to correctly distinguish mild cases from severe cases, failing to record mild metritis cases altogether, or misclassifying a normal cow as diseased. All of these scenarios result in misclassification bias, which usually results in an underestimation of the true association between the disease state and the outcome of interest (Johnson et al., 2014). Our working hypothesis was that disease misclassification from inconsistent recording of metritis occurrence, or failure to record mild metritis, would result in an underestimation of the true effect of metritis on projected milk production in a commercial dairy herd. The objective of this research was to determine the effect of simulated disease misclassification on the estimated effect of metritis on projected milk production in a commercial Holstein dairy herd.

A convenience sample of individual cow data representing 1 yr of calvings $(\mathrm{n}=3,427)$ from 1 Midwestern Holstein herd was exported from DairyComp305 (Valley Agricultural Software, Tulare, CA). To be included in the final set of production models, cows must have calved during the year of interest and must have had milk production results through the second test. Of the 3,427 cows originally evaluated, $98 / 2,451$ (4.0\%), $39 / 849(4.6 \%)$, and $13 / 127(10.2 \%)$ of the cows with no metritis recorded, mild metritis, and severe metritis, respectively, were culled before completing a second milk test, resulting in 3,277 cows with complete data for the modeling exercise. Of the 150 excluded cows, 27 were first lactation and represented $2 \%$ of that parity. For the older cows, 59 were second lactation $(5.1 \%)$ and 64 were from lactation 3 and higher $(6.8 \%)$. This herd was chosen because of its ongoing efforts to consistently and completely record all clinical diseases, including mastitis, hyperketonemia, retained placenta, displaced abomasum, and both mild and severe metritis. The owner and manager is a veterinarian and invested considerable time and effort in training the on-farm staff to carefully examine each cow using a consistent and repeatable approach to help ensure greater consistency with disease diagnosis. The dairy's normal routine was to assess postparturient animals daily for any sign of illness for up to $14 \mathrm{~d}$ following parturition. Any cows that were not eating, appeared dull, or that displayed any evidence of foul vaginal discharge or straining from the rear were examined more completely. Upon palpation per rectum, any cow that had a flaccid uterus containing fetid fluids or possessing a foul watery discharge within $14 \mathrm{~d}$ of calving was diagnosed as having metritis and treated. Cows that appeared clinically normal oth- er than the watery, fetid discharge were administered ceftiofur hydrochloride at a dose of $2.2 \mathrm{mg} / \mathrm{kg}$ i.m. once daily for $5 \mathrm{~d}$. Any cow with metritis that displayed systemic signs of disease, including a rectal temperature greater than $39.4^{\circ} \mathrm{C}$, inappetence, or obtundation, received ampicillin suspension at a dose of $11 \mathrm{mg} / \mathrm{kg}$ i.m. once daily for $5 \mathrm{~d}$. Cows were retrospectively classified into metritis categories based upon the presence or absence of a metritis event and its treatment remark (ceftiofur or ampicillin). Cows receiving ceftiofur for metritis were labeled as mild and those receiving ampicillin for metritis were identified as severe. Cows with no recorded metritis event were identified as not recorded (NR). The information as obtained from the farm's records was considered to contain the true metritis incidence and true severity ( $\operatorname{Tr} \mathbf{S})$.

The TrS model contained 2,353 cows with no metritis recorded, 810 mild metritis cases (24.7\% incidence), and 114 severe metritis cases (3.5\% incidence). First, to evaluate the effect of misclassification bias, we retrospectively randomized $45 \%$ of mild metritis cases $(363 / 810)$ to be classified as NR to represent a scenario of inconsistent disease recording (IR), where not all cases of mild metritis are properly identified and recorded; this set contained 2,716 cows with no apparent metritis recorded, 447 mild metritis cases (13.6\% apparent incidence), and 114 severe metritis cases $(3.5 \%$ incidence). In the second simulation, all mild metritis cases $(810 / 810)$ were changed to NR to represent a scenario of poor disease recording (PR), where only the most severe cases of metritis are being diagnosed and recorded and mild metritis cases are not being identified; this set contained 3,163 cows with no apparent metritis recorded and 114 severe metritis cases (3.5\% incidence). In all models, the number of severe metritis cases (114) remained the same; only the misclassification of mild metritis cases was changed in each of the alternative scenarios. An ANOVA using the standard least squares personality to construct linear models was the analytical approach for analyzing the TrS, IR, and PR data sets separately in JMP Pro 13.2.1 (SAS Institute Inc., Cary, NC). The outcome of interest was second test-day 305-d mature-equivalent milk projection (2nd305ME). This outcome was chosen for several reasons. First, cows with metritis are often culled prematurely, and waiting for a complete $305-d$ production record would result in a biased estimate due to missing data; the second test projection was chosen as a balance between a desire to use more than a single test point and a need to use an earlylactation measurement; finally, the mature-equivalent approach was chosen to allow for a more parsimonious model for all parities without stratification or the use of additional interaction terms. Each model was offered 
Table 1. Herd demographic data for cows and variables that were included in the model exercise simulations

\begin{tabular}{lrc}
\hline Item & No. of cows & \% of herd \\
\hline Lactation group & & \\
1 & 1,310 & 40.0 \\
2 & 1,088 & 33.2 \\
$3+$ & 879 & 26.8 \\
Calf outcome & & \\
Twin & 145 & 4.4 \\
Singleton & 3,132 & 95.6 \\
Health disorder & & \\
Dystocia & 319 & 9.7 \\
Retained placenta & 123 & 3.8 \\
Hyperketonemia & 563 & 17.2 \\
Mastitis & 93 & 2.8 \\
Displaced abomasum & 100 & 3.1 \\
Metritis & 924 & 28.2 \\
\hline
\end{tabular}

${ }^{1}$ Of all animals included in this data set, an average of $8.3 \%$ of animals calved each month $(\mathrm{SD}=0.009$; range $=6.9$ to $9.6 \%$ of herd).

${ }^{2}$ Dystocia $=$ calving ease score $>1$ on a 1 to 5 scale; retained placenta $=$ presence of retained fetal membranes at $\geq 24 \mathrm{~h}$ postcalving; hyperketonemia $=$ blood $\mathrm{BHB} \geq 1.2 \mathrm{mmol} / \mathrm{L}$ within $14 \mathrm{DIM}$; mastitis, displaced abomasum, and metritis all refer to treated clinical diseases diagnosed within first 30 DIM. the predictors of month of calving, lactation group (1, 2 , or $3+$ ), dystocia (calving ease score $>1$ ), calf outcome (twin or singleton), early-lactation clinical disease occurring within the first 30 DIM (retained placenta, displaced abomasum, mastitis, and metritis; Table 1), hyperketonemia (blood BHB $\geq 1.2 \mathrm{mmol} / \mathrm{L}$ ), and all biologically meaningful 2-way interactions, similar to models outlined in Dubuc et al. (2011). Nonsignificant disease variables were removed from the model when $P$ $>0.10$; however, the variable metritis was forced into all models.

In survey work by Kelton et al. (1998), the reported metritis incidences ranged from 2.2 to $37.3 \%$ with a median incidence of $10.1 \%$. In recent work by Santos et al. (2015), in which disease scoring was done by research staff study site monitors, the metritis incidence ranged from 18.5 to $27.6 \%$ across geographical regions. There is a wide range in reported metritis diagnostic procedures (Sannmann et al., 2012), as well as implementation

Table 2. Number of cows and metritis severity classifications for the true severity $(\mathrm{TrS})$ model, and subsequently misclassified in the inconsistent recording (IR) and poor recording (PR) models

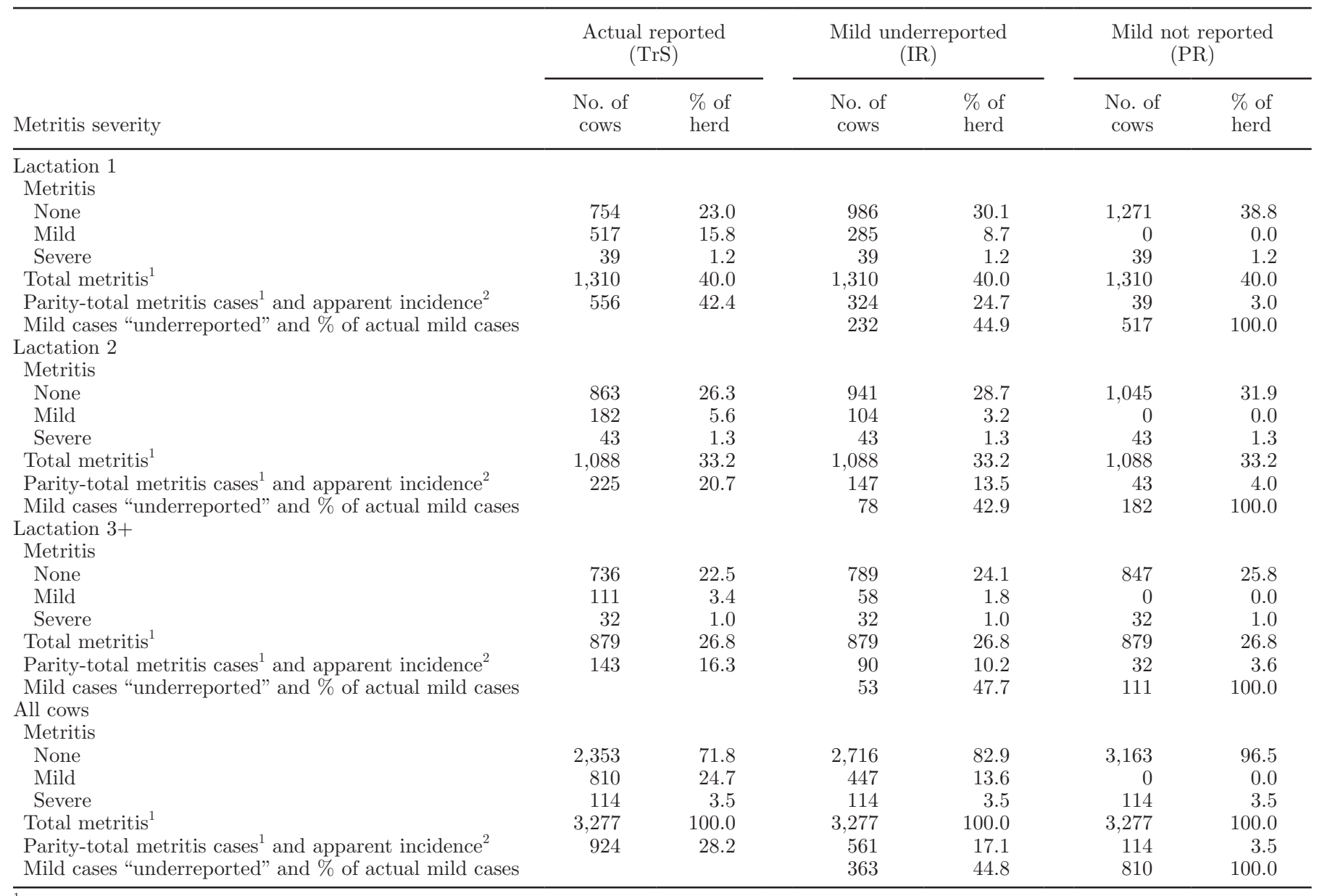

${ }^{1}$ Total metritis within parity group, where total metritis $=$ mild + severe cases.

${ }^{2}$ Apparent metritis incidence within parity group, where incidence $=$ total metritis/category total number of cows. 


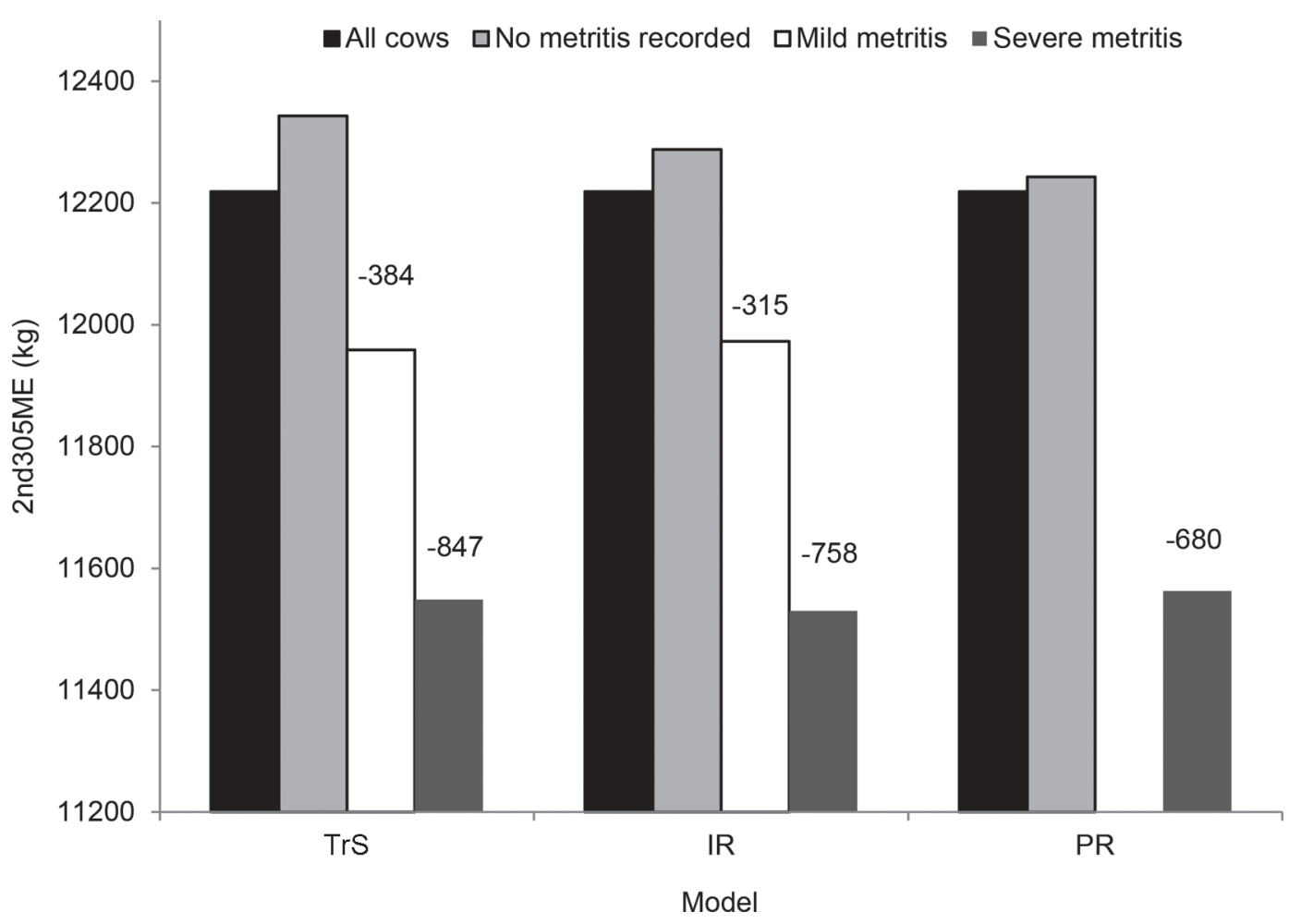

Figure 1. Second test 305-d mature-equivalent milk projection (2nd305ME) for all cows, cows classified as no metritis recorded, mild metritis, or severe metritis for the true severity (TrS) model, and misclassified in the inconsistent recording (IR) and poor recording (PR) models. Negative numbers above the mild metritis and severe metritis columns for each model represent the associated milk loss (kg) for cows with mild or severe metritis in each of the models relative to cows with no metritis recorded.

practices (Espadamala et al., 2016) in the literature. Together, these data suggest an inconsistency in metritis definition and diagnosis within and between herds, further extending observations by Parker Gaddis et al. (2012) that herd-reported disease incidence is underreported. When underreporting or misclassification bias occurs, the association between the disease and the outcome variable is most often biased toward the null hypothesis (Jurek et al., 2005; Johnson et al., 2014; Corbin et al., 2017), thus reducing the observed effect of the disease on the outcome of interest.

Table 2 shows the number of cows classified as no metritis recorded, mild metritis, or severe metritis for the TrS model and subsequently misclassified in the IR and PR models. In the random selection of mild cases to reclassify as no metritis, selections were made without specific regard of parity. However, the proportion of cases selected by parity was not different $(P=0.67)$, with 45,43 , and $48 \%$ of cases selected for lactation 1,2 , and $3+$, respectively. In the current study, based upon the TrS model, adjusting for effects of lactation group, month of calving, retained placenta, hyperketonemia, early-lactation mastitis, displaced abomasum, twins, dystocia, and the interactions of retained placenta $x$ ketosis, and displaced abomasum $\times$ metritis, a case of mild metritis was associated with $384 \mathrm{~kg}$ less $2 \mathrm{nd} 305 \mathrm{ME}$ and a case of severe metritis was associated with 847 $\mathrm{kg}$ less 2nd305ME compared with no reported metritis. The same explanatory variables used in the TrS model were included in both the IR and PR models. In the IR model, a case of mild metritis was associated with $315 \mathrm{~kg}$ less 2nd305ME and a case of severe metritis was associated with $758 \mathrm{~kg}$ less 2nd305ME compared with no metritis. For the PR model, severe metritis was associated with $680 \mathrm{~kg}$ less $2 \mathrm{nd} 305 \mathrm{ME}$ compared with NR. Even though only mild metritis cases were misclassified in the IR and PR models, the underestimated 2nd305ME loss for mild metritis cases in the IR model was $69 \mathrm{~kg} / \mathrm{cow}$, and for severe metritis cases was 89 and $166 \mathrm{~kg} / \mathrm{cow}$ (Figure 1), respectively, compared with TrS. The net effect in terms of milk losses attributable to metritis that would have been missed had the modeled scenarios been real were 180,441 and 330,256 $\mathrm{kg}$ for the herd for IR and PR, respectively. The net effect values were estimated by summing the product of the number of cows by the estimated loss for each case. Therefore, in herds that have inconsistent or poor recording of metritis, we are unable to account for a 
substantial amount of milk loss associated with metritis and would underestimate the effect of this disease when evaluating on-farm records.

Due to the limitations of this data set, even the modeled estimates of losses due to misclassification should be considered as conservative. In the modeled scenarios, comparisons were made between cows based upon a change in the assigned condition, but even the misclassified metritis cows had received antimicrobial therapy. If antimicrobial therapy indeed lessens the negative effect of disease, our modeled estimates of the effect of misclassification themselves are underestimated.

Metritis is not the only disease that is underreported by dairy producers (Parker Gaddis et al., 2012); this concept of misclassification bias can most likely be applied across all transition cow diseases, as similar negative consequence costs are associated with other transition cow diseases (McArt et al., 2015; Rollin et al., 2015; Liang et al., 2017). In conclusion, the misclassification of metritis results in greater bias and underestimates the true association between metritis and milk production, and, as such, underestimates the economic cost of the disease. Improving the definition and recording of metritis, along with other transition cow diseases, can lead to better interpretation of the true effect of disease on dairy herds.

\section{ACKNOWLEDGMENTS}

The authors sincerely appreciate and gratefully acknowledge Dairy Dreams LLC (Casco, WI) and Don Niles, DVM and dairy owner, for the use of their data in this report.

\section{REFERENCES}

Corbin, M., S. Haslett, N. Pearce, M. Maule, and S. Greenland. 2017. A comparison of sensitivity-specificity imputation, direct imputation and fully Bayesian analysis to adjust for exposure misclassification when validation data are unavailable. Int. J. Epidemiol. 46:1063-1072.

Deluyker, H. A., J. M. Gay, L. D. Weaver, and A. S. Azari. 1991. Change of milk yield with clinical diseases for a high producing dairy herd. J. Dairy Sci. 74:436-445.
Dubuc, J., T. F. Duffield, K. E. Leslie, J. S. Walton, and S. J. Leblanc. 2011. Effects of postpartum uterine diseases on milk production and culling in dairy cows. J. Dairy Sci. 94:1339-1346.

Espadamala, A., P. Pallares, A. Lago, and N. Silva-Del-Rio. 2016. Fresh-cow handling practices and methods for identification of health disorders on 45 dairy farms in California. J. Dairy Sci. 99:9319-9333

Fourichon, C., H. Seegers, and X. Malher. 2000. Effect of disease on reproduction in the dairy cow: A meta-analysis. Theriogenology 53:1729-1759.

Johnson, C. Y., W. D. Flanders, M. J. Strickland, M. A. Honein, and P. P. Howards. 2014. Potential sensitivity of bias analysis results to incorrect assumptions of nondifferential or differential binary exposure misclassification. Epidemiology 25:902-909.

Jurek, A. M., S. Greenland, G. Maldonado, and T. R. Church. 2005. Proper interpretation of non-differential misclassification effects: expectations vs observations. Int. J. Epidemiol. 34:680-687.

Kelton, D. F., K. D. Lissemore, and R. E. Martin. 1998. Recommendations for recording and calculating the incidence of selected clinical diseases of dairy cattle. J. Dairy Sci. 81:2502-2509.

Lee, L. A., J. D. Ferguson, and D. T. Galligan. 1989. Effect of disease on days open assessed by survival analysis. J. Dairy Sci. 72:10201026.

Liang, D., L. M. Arnold, C. J. Stowe, R. J. Harmon, and J. M. Bewley. 2017. Estimating US dairy clinical disease costs with a stochastic simulation model. J. Dairy Sci. 100:1472-1486.

McArt, J. A., D. V. Nydam, and M. W. Overton. 2015. Hyperketonemia in early lactation dairy cattle: A deterministic estimate of component and total cost per case. J. Dairy Sci. 98:2043-2054.

Parker Gaddis, K. L., J. B. Cole, J. S. Clay, and C. Maltecca. 2012. Incidence validation and relationship analysis of producer-recorded health event data from on-farm computer systems in the United States. J. Dairy Sci. 95:5422-5435.

Rollin, E., K. C. Dhuyvetter, and M. W. Overton. 2015. The cost of clinical mastitis in the first 30 days of lactation: An economic modeling tool. Prev. Vet. Med. 122:257-264.

Sannmann, I., S. Arlt, and W. Heuwieser. 2012. A critical evaluation of diagnostic methods used to identify dairy cows with acute postpartum metritis in the current literature. J. Dairy Res. 79:436-444.

Santos, J. E. P., P. Oinedo, G. M. Schuenemann, R. C. Bicalho, R. C. Chebel, C. Seabury, J. Fetrow, and W. W. Thatcher. 2015. Improving fertility through genomic selection. Pages 3-9 in Proc. Dairy Cattle Repro. Council. Buffalo, NY. DCRC, Champaign, IL.

Sheldon, I. M., J. Cronin, L. Goetze, G. Donofrio, and H. J. Schuberth. 2009. Defining postpartum uterine disease and the mechanisms of infection and immunity in the female reproductive tract in cattle. Biol. Reprod. 81:1025-1032.

Wittrock, J. M., K. L. Proudfoot, D. M. Weary, and M. A. von Keyserlingk. 2011. Short communication: Metritis affects milk production and cull rate of Holstein multiparous and primiparous dairy cows differently. J. Dairy Sci. 94:2408-2412. 